\title{
The archive and library of the former Italian Central Office for Meteorology and Climatology
}

\author{
M. C. Beltrano ${ }^{1}$, S. Esposito ${ }^{1}$, and L. Iafrate ${ }^{2}$ \\ ${ }^{1}$ Unità di Ricerca per la Climatologia e la Meteorologia applicate all'Agricoltura, Consiglio per la Ricerca e la \\ Sperimentazione in Agricoltura, Roma, Italy \\ ${ }^{2}$ Centro di Ricerca per lo Studio delle Relazioni tra Pianta e Suolo, Consiglio per la Ricerca e la \\ Sperimentazione in Agricoltura, Roma, Italy
}

Correspondence to: M. C. Beltrano (mariacarmen.beltrano@entecra.it)

Received: 22 September 2011 - Revised: 29 February 2012 - Accepted: 12 March 2012 - Published: 4 April 2012

\begin{abstract}
The Paper Archive and Library of CRA-CMA (Agricultural Research Council - Research Unit for Climatology and Meteorology applied to Agriculture) are an important source of meteorological data for climate research.

CRA-CMA's Paper Archive gathers a collection of about 850 historical meteorological datasets. Among them, 40 are nowadays still in progress, 260 are more than thirty years long and 20 exceed one century. Moreover, the specialized Library of CRA-CMA gathers several publications containing meteorological data from many Italian and foreign observatories and an important collection of scientific journals and historical books on Atmospheric Sciences, Geophysics and Agrometeorology published both in Italy and abroad and dating from the second half of the sixteenth century. Even if input data for climate models are generally based on $30 \mathrm{yr}$ long datasets, nevertheless longer observational series (up to 50 or $100 \mathrm{yr}$ ) are a key element to better understand the climate system behavior.
\end{abstract}

Until today, the library described in this paper is a CRA-CMA heritage almost unknown to the international scientific community.

\section{Introduction}

The origin of the current Archive and Library was the establishment in 1876 of the Regio Ufficio Centrale di Meteorologia $(\mathrm{UCM})$ - now CRA-CMA ${ }^{1}$ - whose head office was

\footnotetext{
${ }^{1}$ Office names and acronyms since 1876 :

1876-1887 Regio Ufficio Centrale di Meteorologia - UCM (Royal Central Office for Meteorology)

1887-1923 Regio Ufficio Centrale di Meteorologia e Geodinamica - UCMG (Royal Central Office for Meteorology and Geodynamics)

1923-1939 Regio Ufficio Centrale di Meteorologia e GeofisicaUCMG (Royal Central Office for Meteorology and Geophysics)

1939-1941 Regio Ufficio Centrale di Meteorologia e Climatologia - UCMC (Royal Central Office for Meteorology and Climatology)

1941-1956 Ufficio Centrale di Meteorologia e Ecologia Agraria - UCMEA (Central Office for Meteorology and Agrometeorology)

1957-2007 Ufficio Centrale di Ecologia Agraria - UCEA (Central Office for Meteorology and Agrometeorology)
}

located inside the ancient "Collegio Romano" (founded in the second half of the 16th century by the Jesuit Fathers), in the heart of Rome, where the astronomic and meteorological Observatory of the Pontifical State was run.

UCM founded a national monitoring network which rapidly grew from 50 to 400 stations in 1880 . At the same time, (i) new rules to standardize measures and observations were defined and (ii) the systematic collection of meteorological data was activated. This latter is still in progress enriching the CMA Paper Archive.

Between the late nineteenth and the early twentieth century, thanks to specific international agreements, UCM started to gather meteorological data coming from many European and international weather stations, that, now, are still stored in suitable yearbooks.

2007-today Unità di Ricerca per la Climatologia e la Meteorologia applicate all'Agricoltura - CRA-CMA (Research Unit for Climatology and Meteorology applied to Agricolture of the Agricultural Research Council). 


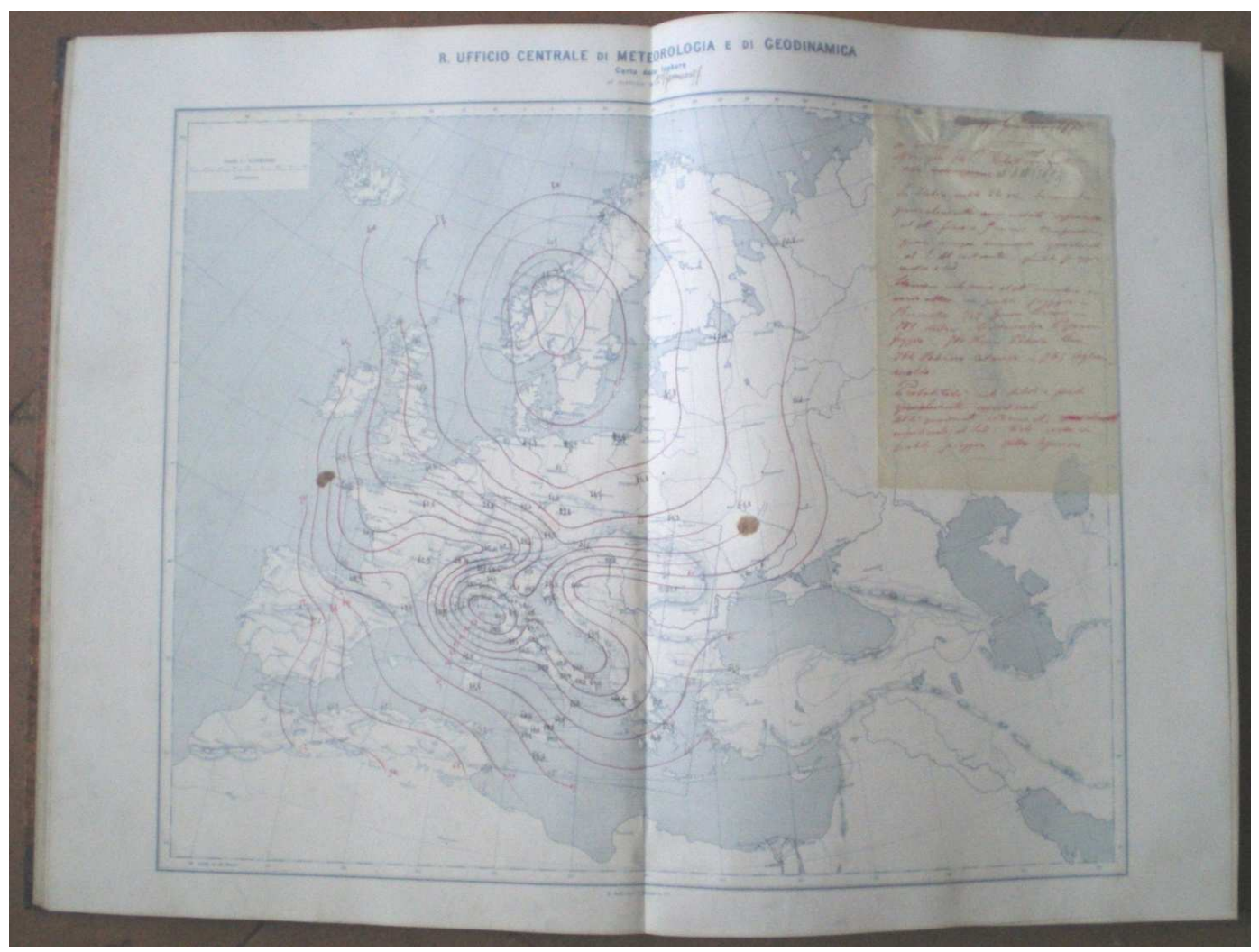

Figure 1. Sample of an early daily isobaric chart. A brief note about the weather forecast for the next day was added to each map.

The early UCM goals were: (1) to carry out studies on Italy weather and climate using the above-mentioned meteorological information and (2) to produce weather forecasts called "Presagi" (forecast of future events). These activities were carried out, gathering data from meteorological stations, updating weather charts and producing daily forecasts, broadcasted by telegraph throughout Italy and Europe.

These original maps and messages are still kept at the CMA Library (Fig. 1).

\section{The CMA Paper Archive}

The CMA Paper Archive (Fig. 2) collects about 3300 folders, each containing a yearly collection of ten-days observation forms, filled by volunteer observers, producing daily or subdaily hand written records of air temperature, relative humidity, atmospheric pressure, wind speed and direction, precipitation, sunshine duration, solar radiation, evaporation and visual observations (cloud cover and type, snow depth and so on).

Some of the early observatories belonging to the UCM network are nowadays still working. The Archive holds more than 850 series. Among them, 260 are longer than thirty years, 20 are longer than one hundred years and 40 are still in progress at present.
For each standard meteorological variable the Archive has more than six millions elementary measurements coming from Italy or other countries like the former Italian territories of Balkans, the former Yugoslavia, Greece and Albania. Furthermore, meteorological data from the Italian Colonies of Africa (Ethiopia, Libya and Somalia) are also held in the CMA Library.

One section of the observation forms, named Note speciali sui fenomeni meteorologici (Special notes on meteorological phenomena), owing to remarks concerning special weather events, is written by the observer in his own words. Sometimes these remarks show colorful or poetic comments about atmospheric phenomena. Moreover, specific comments about local historical events can be read in these scientific forms, that, in this way, become noteworthy historical and cultural documents (Fig. 3).

The observational forms also report information about replacement of the observer, shift in reporting time, changes in site characters, failure and replacement of instruments, and so on. Those metadata allow us to trace the history of each weather station and provide a key for critical analysis of data, improving the validation and standardization processes.

As far as written above, the Paper Archive represents a valuable source of meteorological data of both past and present. CRA-CMA is spending great efforts to implement 


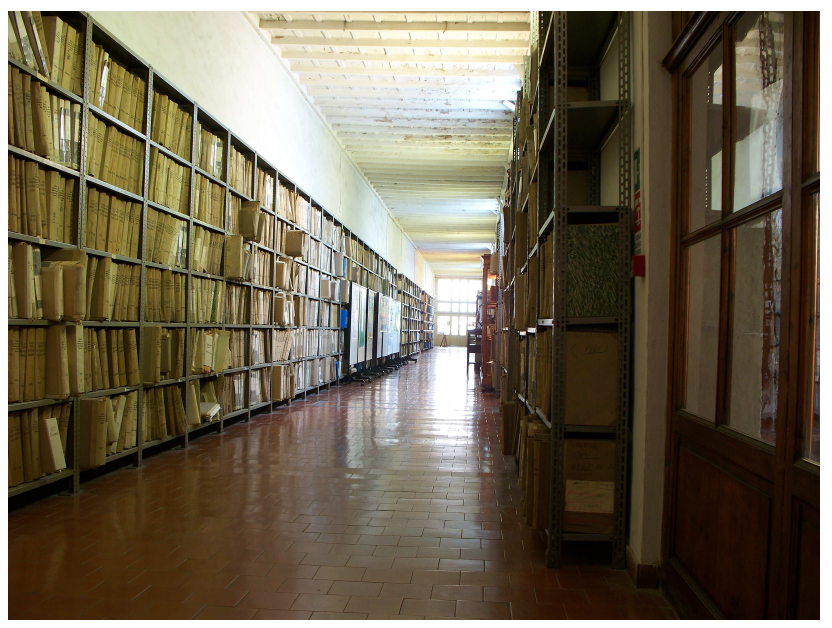

Figure 2. The seat of the Meteorological Archive at CRA-CMA.

the digitization of paper data, in order to constantly update its electronic databank named National Agrometeorological Data Base $(\mathrm{BDAN})^{2}$; digitization is a priority program for $\mathrm{CMA}$ and it will continue in the future. At present, (we assume that) less than $30 \%$ of the whole original Paper Archive has been processed.

However, digitization only covers the main meteorological variables, as temperature, precipitation, pressure, sunshine, wind and leaves behind all auxiliary information like the witness remarks mentioned above, the visual observations, the type and duration of weather events and others metadata. Since scanning and image capture of paper forms are the best approach to preserve their full content, a program for the creation of an "Image-file Archive" is almost ready to start.

The CMA Archive keeps another relevant collection: the Thunderstorms postcards (Fig. 4) compiled and sent by several observers to the Office between 1880 and 1970. It represents a source of interesting information about these severe weather phenomena. Postcards are not fully cataloged, but a corpus of about ten thousand thunderstorms postcards is estimated.

Furthermore, between 1887 and 1939, UCM was charged to manage the National Seismic Service. In this role, it received information about all earthquakes occurred in Italy by special postcards (Fig. 5) sent from numerous geodynamic observatories and seismic stations located throughout the Country. The collection consists of about 5000 seismic postcards, cataloged by the National Institute of Geophysics and Volcanology (INGV) of the Italian National Research Council (CNR).

\footnotetext{
${ }^{2}$ Several datasets of the National Agrometeorological Data Base (BDAN) are available at the web site: http://www.cra-cma.it.
}

\section{The CMA Library}

The CMA Library (Fig. 6) digs its roots in the early years of the Collegio Romano Astronomical and Meteorological Observatory. In fact, the Library comes from the Earth Sciences collection of the early Observatory (Fig. 7) integrated with later meteorological and geodynamic books. In 1879 this bibliographic collection became the core of the UCM Library.

Thereafter, the history of the Library can be identified with the history of the Office. During the period in which UCM held the responsibility for the "National Geodynamic Service" (1887-1939), a lot of books and periodicals on seismology, volcanology and geology were acquired by the Library, either from Italy and abroad.

In 1939, when the geodynamic competences of UCMG were transferred to the ING (now INGV), some of the geophysical and geological collections were transferred to this institution. Afterwards UCM focused its activity on the fields of ecology and meteorology applied to agriculture. Hence, over the years, the CMA Library has been enriched with many valuable and rare collections of books and periodicals on meteorology, climatology and phenology, becoming the leading Italian Library in these fields.

The Library collects now more than 15000 historical texts related to meteorology; most published in the nineteenth century and in the early twentieth century. Moreover, some historical books on geophysics date back to the second half of the sixteenth century.

The collection contains a large variety of books on synoptic and dynamic meteorology, such as historic texts by Louis Cotte, Giuseppe Toaldo, Matthew Fontain Maury, Elias Loomis, Angelo Secchi, Robert Fitz Roy, Urbain Le Verrier, Christophorus Buys Ballot, Adolphe Quetelet, Edme Hippolyte Marié-Davy, William Ferrel, Hermann von Helmholtz, Luigi De Marchi, Adolf Sprung, Wilhelm van Bebber, Ralph Abercromby, Léon Teisserenc de Bort, Alfred Angot, Francesco Vercelli, Vilhelm and Jacob Bjerknes, Lewis Fry Richardson, Jules Charney, Ernesto Gherzi.

Several of these books, relevant for climatology and climate change, constitute the written heritage of notable scientists, such as Giovanni Targioni Tozzetti (1712-1783), Vincenzio Chiminello (1741-1815), Jean B. J. Fourier, John Tyndall, Svante Arrhenius, Louis Agassiz, Luigi De Marchi, Filippo Eredia, Gustav Hellmann, Ellsworth Huntington, Guy S. Callendar, Milutin Milankovic, Gordon Manley, Hubert H. Lamb, Edward N. Lorenz, Ezio Rosini, Sabino Palmieri and Vittorio Cantù.

Among Italian periodical publications available in the Library, the most important Italian ones are listed below. Many of them were issued by the same Regio Ufficio Centrale di Meteorologia e Geodinamica (UCMG). 


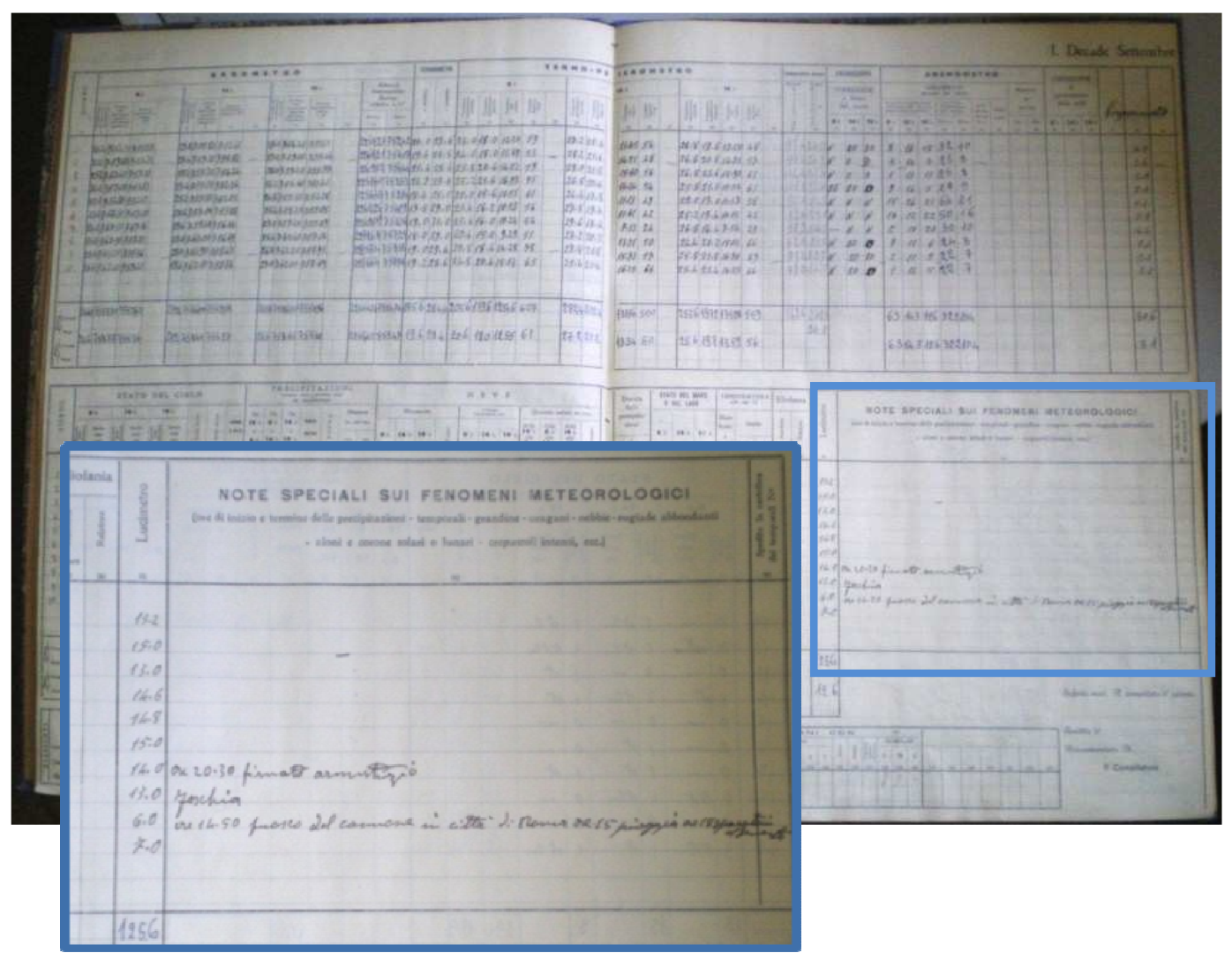

Figure 3. Collegio Romano Observatory: year 1943, September, the first ten days observation form. Weather notes and news about the Second World War are reported in "Special notes on the weather": 7 September, 08:30 p.m. - "The armistice" (Italy - Allied Countries) was signed; 8 September - Haze; 9 September, 02:50 p.m. "Cannon shots in Rome"; 03:00 p.m. "Rain"; 06:00 p.m. "Shooting in the Italian Senate".

- Bullettino Meteorologico dell'Osservatorio del Collegio Romano (Weather Bulletin of Collegio Romano's Observatory) (1862-1878) - issued to give visibility and access to meteorological data and Italian studies on meteorology and terrestrial physics. This magazine is the expression of the excellent work made by the Pontifical Meteorological Network founded by Jesuit Father Angelo Secchi in 1855, at the Collegio Romano Observatory, the first modern storms forecasting service in the world indeed.

- Bullettino Meteorologico dell'Osservatorio del Real Collegio Carlo Alberto in Moncalieri (Meteorological Bulletin of Moncalieri's Observatory) (1865-1923) the first scientific publication of its kind in Northern Italy, similar to the Collegio Romano Bulletin. This periodical was the journal of a private meteorological network established by Father Francesco Denza, covering all the Italian regions (Corrispondenza Meteorologica Italiana delle Alpi e degli Appennini). This network operated in parallel with the UCM one.
- Meteorologia Italiana (Italian Meteorology) (18651878) - scientific magazine published by the Ministry of Agriculture, Industry and Commerce's Climatological Service. This first governmental periodical on meteorology and climatology mainly contains meteorological data. From 1867 a Supplement on the Italian meteorology (Supplemento alla Meteorologia Italiana) was added to the journal, issuing relevant meteorological analyses and original notes and memories on meteorological topics.

- Annali del R. Ufficio Centrale di Meteorologia e Geodinamica (Annals of the Royal Central Office for Meteorology and Geodynamics) (1879-1935) - issued by $\mathrm{UCM}$, this collection of volumes is the prosecution of Meteorologia Italiana. Each yearly volume is subdivided in three parts. The first part contains memories and papers on meteorology and geodynamics, produced by the scientific staff of the UCM and other Italian meteorologists and geophysicists. Meteorological works are referred to several different topics: 


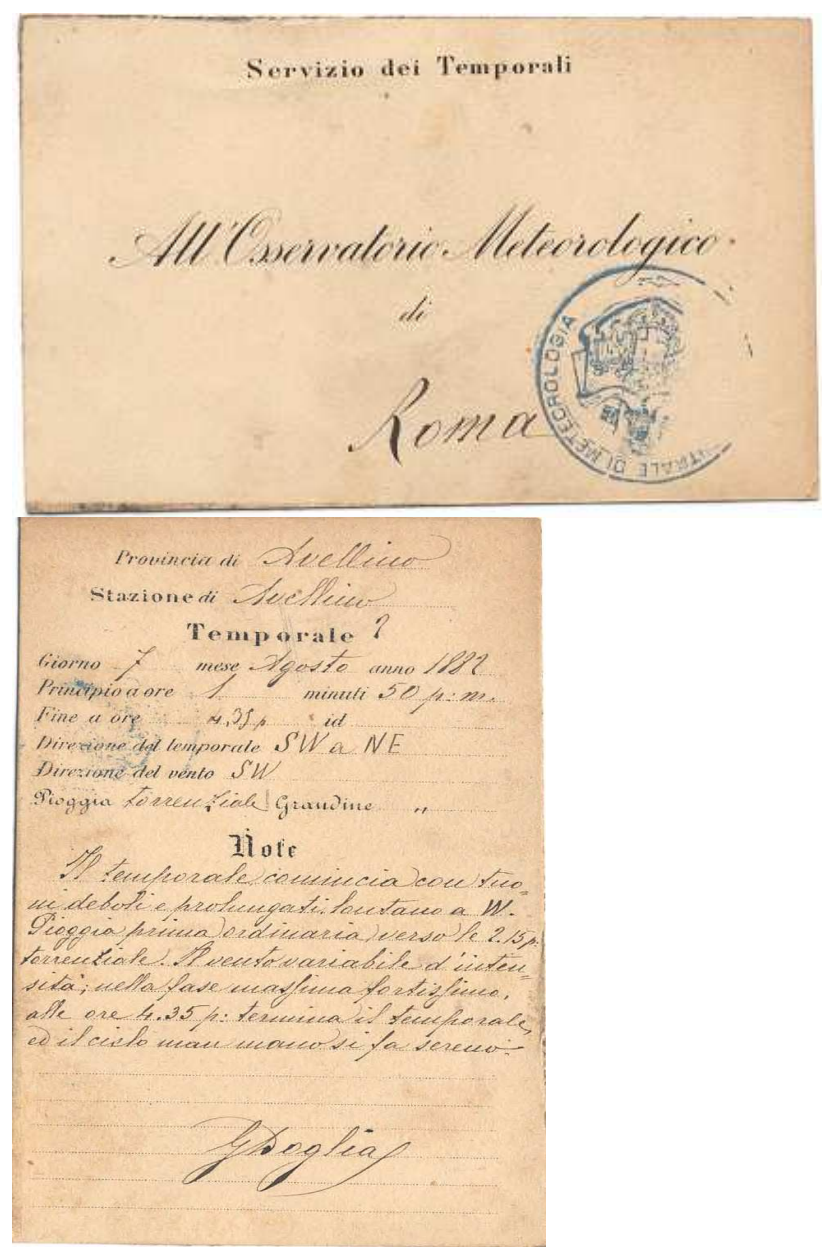

Figure 4. Sample of a Thunderstorms postcard. Front: Thunderstorms Service - Meteorological Observatory Rome. Back: Province Avellino, Station of Avellino, Thunderstorm of Day 7, Month August, Year 1882. Start at hours 1 minutes 50 p.m. End at hours 04:35 p.m., id = Thunderstorm direction SW To NE. Wind direction SW. Rain Torrential. Hail = Remarks: thunderstorm starts with weak and protracted thunders far at W. Rain at the first time regular, about at 02:15 p.m. torrential. Wind of changeable intensity; in the maximum phase very strong. At 04:35 p.m.: thunderstorm stops and sky gradually becomes clear. Signature not understandable.

- researches on thunderstorms in Italy, authored by Schiaparelli, Frisiani and Pini,

- pioneering studies on theoretical and dynamic meteorology, mostly by Luigi De Marchi,

- contributions to the knowledge of Italian Climate, by Filippo Eredia and Elia Millosevich,

- pioneering memories on the emerging field of Aerology (Aerological Observatory of Pavia),

- researches about terrestrial magnetism in different Italian regions by Ciro Chistoni and Luigi Palazzo.

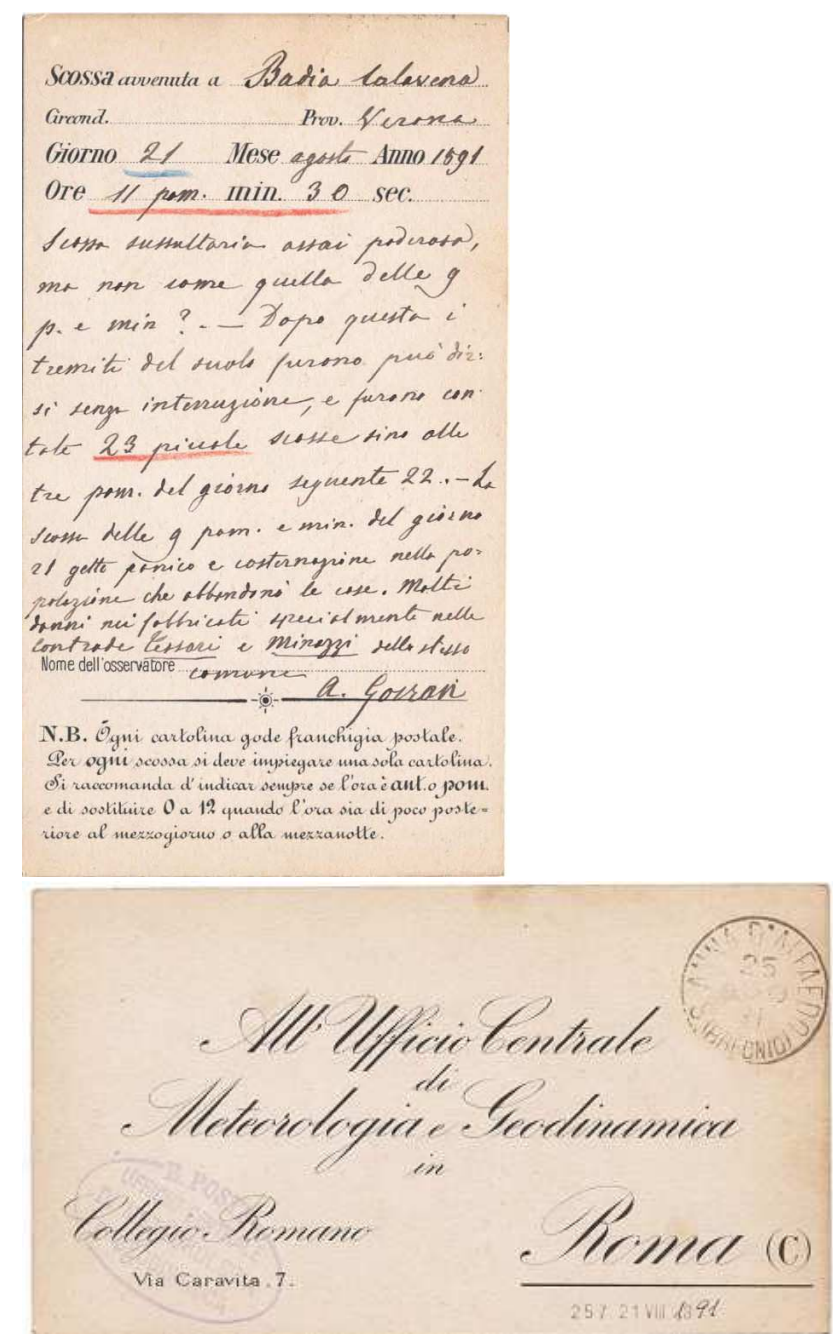

Figure 5. Sample of a Seismic postcard. Front: to Central Office for Meteorology and Geodynamics In Collegio Romano Via del Caravita, 7 Roma. Back: earthquake occurred at Badia Calavena District $=$ Province Verona, Day 21, Month August, Year 1891, hours 11:00 p.m. min $30 \mathrm{sec}$.... Very powerful sussultatory quake, but not like those of 09:00 p.m. and min. ?. After this [...] soil quaked without interruption and we counted 23 small quakes up to 03:00 'o clock in the afternoon of the following day 22. The quake at 09:00 p.m. of $21 \mathrm{st}$ brought panic and consternation among the people who abandoned houses. Many damages to buildings, especially in quarters Cessari and Minazzi of the same town. Observer name: A. Govran.

The remaining parts of the Annali are devoted to meteorological data recorded by the UCM network.

- Bollettino Meteorico Giornaliero (Daily Weather Bulletin) (1879-1927) - Published by UCM, it was issued since 30 November 1879 in order to gather daily weather data from main Italian and foreign observatories. On 1 August 1880 the number of contributing stations was substantially increased to provide a summary 


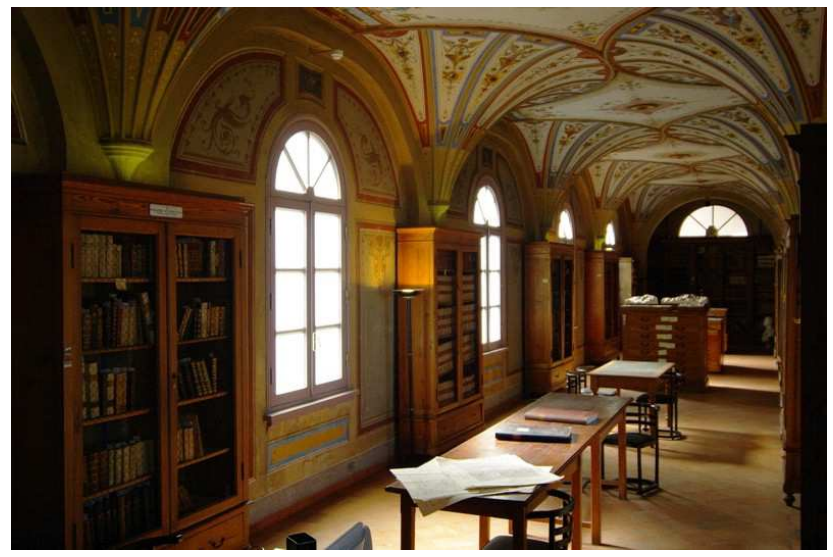

Figure 6. The Library - "the Tacchini Gallery".

of weather conditions in Italy and Europe, as well as a specific forecast dispatch ("Presagio"). Further additions and modifications gave to the journal the final form of a four sided lithographed sheet with daily isobaric and isothermal charts of the Mediterranean Region and one European isobaric chart. A daily broadcast of the "Presagio" was carried out by telegraph to main Italian observatories and harbourmasters (from 1 April 1927, this kind of broadcast was prosecuted by the Weather Office of the Air Force Ministry).

Rivista Meteorico-Agraria Decadica (Ten-days Agrometeorological Magazine) (1879-1916) - published by UCM, it showed, for a ten days period, the European barometric situation, the weather conditions in Italy, such as extreme temperatures, cloudiness, precipitation, etc., offering an interesting overview of crop growth and development for the different agricultural areas of our Country. Each magazine was improved with a map showing average isotherms and the rainfall distribution in Italy. Short agrometeorological notes were also published sometimes as an appendix.

Many Italian and foreign periodicals on Aerology, Oceanography, Geography, Geology, Seismology, Volcanology, as well as many early weather charts from the second half of the 19th centuries of both historical and scientific interest are also stored in the CMA library. Moreover, the Library contains numerous conference papers, working reports and monographs produced by UCM researchers and employees since 1879 . It should also be noted that the Library holds some original manuscripts, unpublished correspondences (19th and 20th centuries) and some interesting miscellaneous collections, e.g. more than fifty volumes containing memoirs and papers on Meteorology and Geophysics, written by the greatest Italian scientists of the 19th and 20th centuries, such as Domenico Ragona, Pietro Tacchini, Luigi Palazzo, Giuseppe Mercalli,

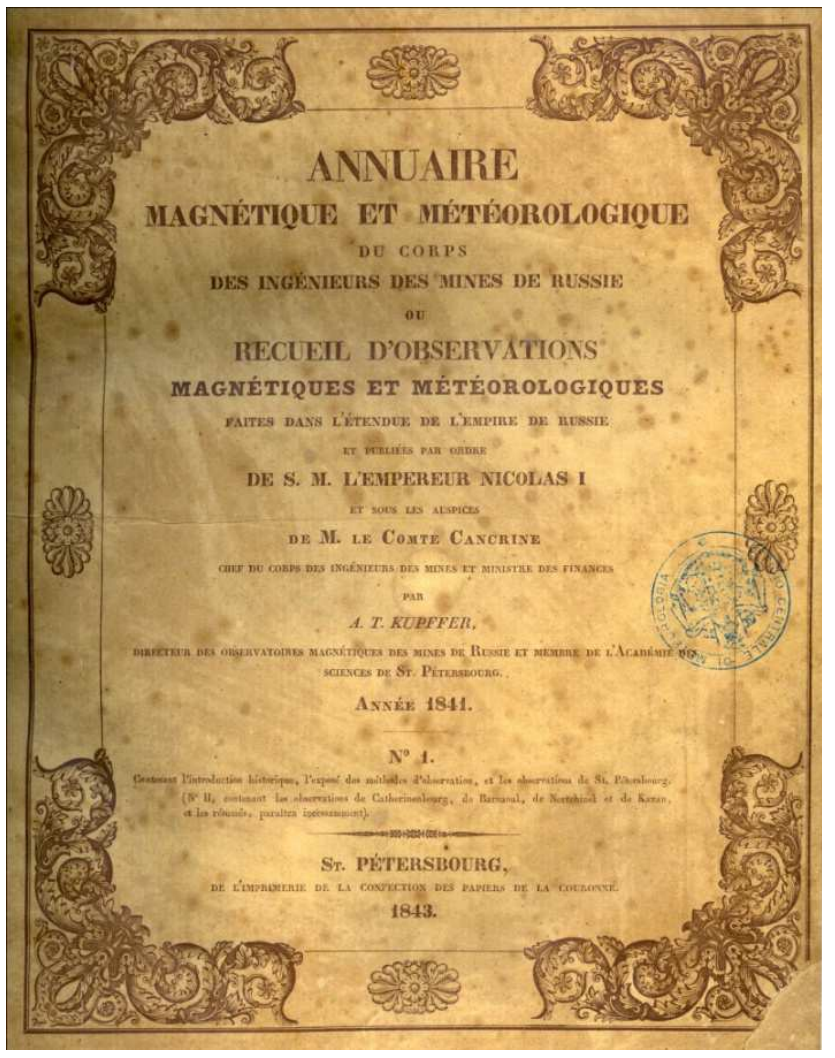

Figure 7. Magnetic and Meteorological Yearbook, St. Petersburg, 1841.

Mario Baratta, Alfonso Cavasino, Ludovico Marini, Emilio Oddone, etc.

Over the years, the Library consultation has been a valuable aid to many experts and researchers in geophysics and meteorology to produce original studies, leading to the redaction of new books, articles, essays and academic works.

It has been recently learned that among the scholars who attended the Library, there was the young Enrico Fermi (1901-1954). During the summer of 1918 Fermi attended his studies at the Library to prepare for the admission exams of Scuola Normale Superiore di Pisa. A key step in his preparation was the study of a French edition of the Treaty of Physics by Orest D. Chwolson, professor at the Imperial University of St. Petersburg. In Rome only two copies of this work were probably available: one in the Library of the Institute of Physics at via Panisperna, not consultable by simple students like Fermi, while the other copy was and is still held in the CRA-CMA Library. Filippo Eredia (Fermi's teacher of physics at the school "Liceo Umberto" in Rome and at the same time responsible for the "Servizio Presagi" at UCM) made the book available to Fermi, which spent most of that summer immersed in reading this Treaty in the CMA Library.

At present, the CMA Library is known as the "Central $\mathrm{Li}$ brary of the Italian Meteorology", because it is the largest Italian collection in atmospheric sciences, the main Italian 
memory of the historical tradition for Meteorology and one of the main bibliographic depository for Geophysics.

The Library is about to join the National Library Service $(\mathrm{SBN})$, in order to get more visibility and make its heritage more accessible to researchers.

\section{Concluding remarks}

The Library and Paper Archive of CRA-CMA are a rich repository of historical meteorological data. Climatic information is insufficiently known and by consequence largely under-exploited by the scientific community. On this basis, CMA's main goals are (i) to give and ease access to the large variety of the historical weather data of the Paper Archive and Library and (ii) also to raise credit abroad and (iii) become a fruitful authorship for the international research on historical climatology.

Several projects have been planned in order to achieve a significant exploitation of these data. More specifically, the ongoing digitizing program represents a first step to draw up at European scale the following climatic studies, also useful to evaluate the impact of climate change on growing crops:

- analysis of climate dynamics in a comparative historical perspective, with special regard to the EuroMediterranean area;

- recognition of daily atmospheric circulation patterns at sub-synoptic scale and mesoscale;

- spatialisation of secular temperature and pressure fields at mesoscale;

- generation of daily datasets, useful, for example, as input for phenological or crop production models;

- generation of datasets of phenological observations useful for phenological models validation.
At present CMA is acknowledged in Italy as an important institution providing reference and consulting services on meteorological and climatic data to Italian universities, agencies and other national institutions.

This presentation would enhance the information exchange and achieve new international relationships and cooperations.

Acknowledgements. The Authors are very grateful to Luigi Mariani and Gabriele Cola for the linguistic revision of this paper.

Edited by: I. Auer

Reviewed by: M. Maugeri and another anonymous referee

The publication of this article is sponsored by the European Meteorological Society. 